\title{
MOVIMENTO DE ENCLAUSURAMENTO: O HOSPITAL GERAL COMO DISPOSITIVO PARA A ESCONJURAÇÃO E O CONFINAMENTO DOS RISCOS SOCIAIS
}

\begin{abstract}
Resumo: Desde o dealbar da modernidade muitas foram as medidas implementadas pelos poderes públicos europeus com o intuito de resolver os problemas de segurança surgidos em consequência da vulnerabilidade adstrita a uma multidão de miseráveis libertados e não absorvidos pela indústria. De entre as mesmas, gostaríamos de dedicar especial atenção ao movimento de enclausuramento. Um movimento que, não obstante ser característico de outros espaços europeus, em França se desenvolveu de um modo mais clarividente, como medida de precaução social. Assim, será nossa intenção mostrar como, a partir da segunda metade do século XVII e por mais de um século, o Hospital Geral de Paris se consubstanciou como a condição sine qua non para a promoção da segurança do corpo social. Isto é, buscar-se-á expor como ao longo deste período o dispositivo hospitalar, ultrapassando as funções que inicialmente lhe estavam adstritas, se transformou no símbolo máximo do enfrentamento dos riscos sociais em França.
\end{abstract}

Manuel Menezes

Palavras-chave: Enclausuramento, Hospital, Pobreza, Riscos Sociais

\section{ENCLOSURE MOVEMENT: GENERAL HOSPITAL AS A DEVICE FOR EXORCISE AND CONFINE SOCIAL RISKS}

\begin{abstract}
Since the beginning of modernity many measures have been implemented by European public authorities with the aim of resolving the problems of security that have arisen as a result of vulnerability attribute of a crowd of miserable released and not absorbed by the industry. Among those measures, we would like to pay particular attention to the
\end{abstract}

\footnotetext{
${ }^{1}$ Doutor em Ciências da Comunicação (especialidade de Comunicação e Cultura) pela Faculdade de Ciências Sociais e Humanas da Universidade Nova de Lisboa. Docente no ISMT.
} 
movement of enclosure. This is a movement that, despite being characteristic of other areas of Europe, in France it has developed more deeply, as a social precautionary measure. Thus, it will be our intention to show how, from the second half of the 17th century and by more than a century, the General Hospital of Paris is crystallized as the sine qua non condition for the promotion of safety of the social body. That is, we seek to expose how, during this period, the hospital, surpassing the functions that were initially defined, has become the ultimate symbol of confrontation of social risks in France.

Keywords: Enclosure, Hospital, Poverty, Social Risks

\section{NOTA INTRODUTÓRIA}

«Ao longo da história da modernidade, a mobilidade e as migrações da força de trabalho perturbaram as condições disciplinares que eram impostas aos trabalhadores. E o poder exerceu a sua violência máxima contra a mobilidade em causa»

(Antonio Negri et all, 2000)

A partir de meados do século XIV começaram a surgir na Europa todo um conjunto de medidas que, conjugando poder e saber, se transmutaram em técnicas a serem aplicadas às populações perigosas visando o controlo e, posteriormente, a governação das mesmas. Das mesmas fizemos uma análise aprofundada numa outra obra (Manuel Menezes, 2009). Aqui interessa-nos dar conta de como na sequência dessas primeiras políticas públicas para a gestão e enfrentamento dos riscos sociais viriam a emergir em diversos pontos da europa ações mais drásticas que culminaram no enclausuramento de um coletivo apreendido como produtor de riscos sociais que colocava em causa a coesão social.

Antes de nos adentrarmos na análise do movimento de enclausuramento propriamente dito, interessa sinalizar que, ao longo de mais de 200 anos, tanto as reformas levadas a cabo ao nível da organização e implementação dos socorros como, na vertente repressiva, a interdição da mendicidade ou a sua permissão sob regulamentação estrita, por um lado, e as tentativas várias de intimidação, dissuasão (por via das penas severas aplicadas aos vagabundos e o seu reenvio para as localidades de origem/residência ou, ainda, o banimento do país no caso 
dos estrangeiros), por outro, mostraram-se infrutíferas na resolução do problema da pobreza/vagabundagem.

Os pobres enquanto elementos inerentes da paisagem urbana ${ }^{2}$ não deixaram de ser uma realidade crescente (facto esse reconhecido pela maioria dos atos legislativos). Ao nível da organização e implementação dos socorros, o fracasso deveu-se, em parte, à existência de uma desproporção incomensurável entre os recursos afetos aos mesmos e os realmente necessários para fazer face às necessidades sentidas por todos aqueles que se encontravam numa situação miserável. No respeitante à vertente repressiva, o malogro pode ser correlacionado com os hiatos existentes entre os diplomas e a sua aplicação prática, porquanto, por um lado, devido a resistências várias enraizadas em práticas culturais ${ }^{3}$ e/ou à evanescente organização do aparelho «policial», alguns deles não chegaram a passar do papel ou quando se buscou a implementação os resultados práticos ficaram aquém do pretendido. Por outro, a impotência, ineficácia na aplicação adequada da panóplia de legislação que paulatinamente foi sendo promulgada deveu-se ao facto de com essas medidas não se atacar a raiz das problemáticas em questão, dado por intermédio das mesmas se ter intentado, contraditoriamente, colocar na esfera do trabalho aqueles que, por definição, dela eram excluídos (Robert Castel, 2000). Isto é, a esfera do trabalho em vez de ser encarada como a fonte do problema, dado gerar o não-trabalho e, por conseguinte, a pobreza, era apreendida como a solução necessária para o erradicar dessa mesma pobreza e dos riscos a ela associados.

Deste modo, o aumento contínuo, por razões socioeconómicas, da problemática da pobreza/vagabundagem, evidenciando a existência crescente de um problema intrinsecamente insolúvel, implicou a adoção de novas estratégias, designadamente o reforço do trabalho forçado e a institucionalização. Se a localização ou retorno à origem e as punições não resolviam, não conseguiam domesticar o flagelo da pobreza/vagabundagem, aos poderes públicos «restava» uma última

\footnotetext{
${ }^{2}$ Segundo a aceção foucaultiana a mendicidade e a vagabundagem consubstanciaramse, essencialmente, como um problema urbano.

${ }^{3}$ De acordo com Michel Foucault «[...] no Antigo Regime, os diferentes estratos sociais tinham cada um a sua margem de ilegalidade tolerada: a não-aplicação da regra, a inobservância de inúmeros éditos ou ordenações eram condição de funcionamento político e económico da sociedade. [... Essa ilegalidade,] ora se revestia de uma forma absolutamente estatutária - que fazia dela não tanto uma ilegalidade quanto uma isenção regular: eram os privilégios concedidos aos indivíduos e às comunidades. Ora tinha a forma de uma inobservância maciça e geral que fazia com que durante dezenas de anos, séculos às vezes, ordenações podiam ser publicadas e renovadas constantemente sem nunca chegar à aplicação» (1975-a: 76; cf. Robert Castel, 1978).
} 
solução - o enclausuramento dos indivíduos e, com isto, dos riscos sociais em que os mesmos se traduziam para o bom funcionamento da sociedade. As vicissitudes do combate até aí travado, forçaram a opção por uma medida até então utilizada subsidiariamente como meio de punição e que só mais tarde se viria a generalizar para os delitos comuns ${ }^{4}$. Estava dado o primeiro passo para o que Michel Foucault (1972) denominou de Grande Enclausuramento. Atingido o grau zero da tolerância, já não bastava a repressão e o controlo do movimento/ação e/ou a detenção pontual. Estas, apesar de continuarem a ser defendidas e postas em prática, foram complementadas por outras cujo pressuposto básico era o de excluir do corpo social uma massa heterogénea de indivíduos que se consubstanciavam como uma ameaça para esse mesmo corpo, ou seja, exilar desse corpo tudo o que lhe era estranho, o que não se coadunava com a ordem social, os «a-sociais», o «de-fora» (Gilles Deleuze, 1998; Robert Castel, 1978) ${ }^{5}$.

Se até aqui o internamento tinha sido timidamente proclamado e esporadicamente aplicado, a partir de agora, o binómio exclusão/enclausuramento, passa a ser concretizado de um modo regular (à margem do sistema judicial ${ }^{6}$ por via do dispositivo hospitalar enquanto símbolo máximo do combate contra os riscos sociais. O desejo de concretização deste intento acabaria, no entanto, por conduzir a uma expansão das intenções iniciais, ou seja, já não só asilo e atelier de trabalho, mas também «[...] uma instituição moral encarregada de castigar, de corrigir uma certa "falha" moral que não merece o tribunal dos homens mas que não poderia ser corrigida apenas pela severidade da

\footnotetext{
${ }^{4}$ Sobre este aspeto, cf. Michel Foucault (1973; 1975-a).

${ }^{5}$ Recorrendo ao que denomina de «modelo de exclusão do leproso» predominante durante a Idade Média, no sentido de uma prática social que «comportava primeiro uma divisão rigorosa, um distanciamento, uma regra de não-contacto entre um indivíduo (ou grupo de indivíduos) e outro. Era de um lado, a rejeição desses indivíduos num mundo exterior, confuso, fora dos muros da cidade, fora dos limites da comunidade. Constituição, por conseguinte, de duas massas estranhas uma à outra. E a que era rejeitada, era rejeitada no sentido estrito nas trevas exteriores. Enfim, em terceiro lugar, essa exclusão do leproso implicava a desqualificação - talvez não exatamente moral, mas em todo caso jurídica e política - dos indivíduos assim excluídos e expulsos»(1975-c: 54); para Michel Foucault ganha plausibilidade a hipótese de esse modelo ainda se encontrar historicamente ativo aquando do início do grande enclausuramento.

${ }^{6}$ No sentido em que o «encarceramento extrajudiciário», i.e., «as "casas de força", os hospitais gerais, as "ordens do rei" ou as do chefe de polícia, as cartas timbradas obtidas pelos notáveis ou pelas famílias [passam a constituir] toda uma prática repressiva, justaposta à "justiça regular" e ainda mais frequentemente oposta a ela» (Michel Foucault, 1975-a: 106).
} 
penitência. O Hospital Geral tem um estatuto ético» (Michel Foucault, 1972: 74).

\section{LOCUS DA GÉNESE DO ENCLAUSURAMENTO}

O movimento despontou no norte da Europa. Um dos primeiros países a adotar o mesmo foi a Holanda e, posteriormente, a Bélgica. Entre os finais do século XVI e os inícios do século XVII, várias foram as cidades a erigir Tuchthuis (casas de correcção/tucht), cujos modelos mais conhecidos seriam as Rasphuis e Spinhuis ${ }^{7}$, nomeadamente as de Amesterdão (1596), Haarlem (1609), Utrecht (1616), Bruxelas (por volta de 1623), Ypres e Bruges (em 1627). Numa gravura de 1662, é possível ver uma instituição masculina (figura 1).

\section{Figura 1}

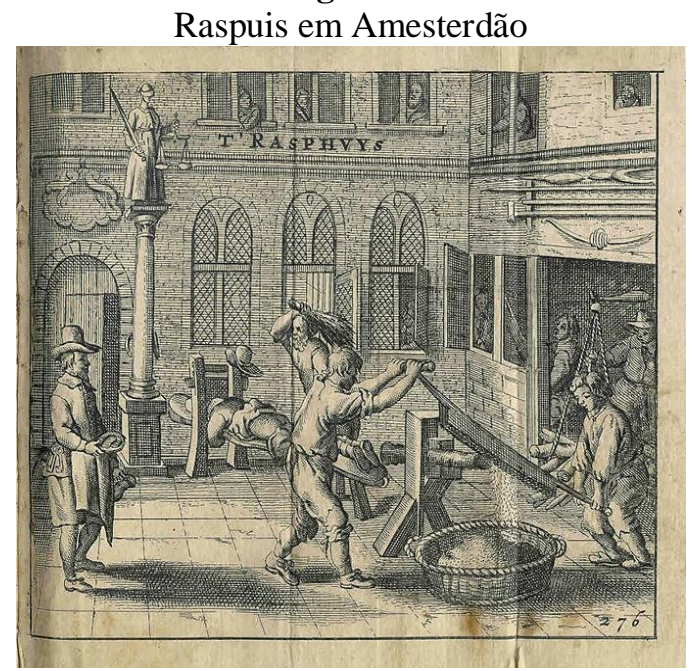

Fonte: Melchior Fokkens (1662).

De pequena dimensão (os internos rondavam, em média, a centena), estas instituições eram reguladas por um regime extremamente severo ${ }^{8}$

\footnotetext{
${ }^{7}$ Nas primeiras, destinadas aos homens, o trabalho correlacionava-se com a obtenção de serradura de madeiras tropicais corantes (pau-brasil) para a fabricação de tinta para tecidos; as mulheres, internadas nas segundas, dedicavam-se, essencialmente, a trabalhos de tecelagem, fiação e costura.

${ }^{8}$ Do qual, na dimensão punitiva, a cela-de-água é somente um exemplo. Uma cela onde estava constantemente a entrar água, que só podia ser escoada por via do manuseamento constante de uma bomba.
} 
onde o objetivo primo era a correção pelo trabalho e por via da instrução religiosa'; as mesmas possuíam distintas secções que, de per si, conectavam objetivos diferenciados: uma para os mendigos, outra para os menores institucionalizados pelas famílias para serem corrigidos, outra para as mulheres mendigas, alcoólicas ou prostitutas. Isto é, simultaneamente asilo para os pobres, manufatura de trabalho $^{10} \mathrm{e}$ instituição penal (Louis Rivière, 1902; Léon Lallemand, 1910).

Estas instituições viriam a servir de modelo a outros estabelecimentos abertos em vários países, nomeadamente na Alemanha. Aqui, o movimento ocorreu um pouco mais tardiamente. Embora existam indicadores da construção de uma primeira Zuchthaus em Lübeck (1601) e na cidade de Hamburgo nos anos 20 do século XVII, só a partir da segunda metade deste século é que as mesmas começaram a generalizarse: Bâle (1667), Breslau (1668), Frankfurt (1684), Spandau (1684), Königsberg (1691) (Michel Foucault, 1972). Consubstanciando-se como um misto de abrigo para pobres e casa de correção para os desligados, as instituições alemãs buscaram, tal como as suas congéneres flamengas, responder igualmente a imperativos económicos. Facto este, que pode conduzir à aceitação da tese segundo a qual o modelo de política social impulsionador de instituições onde, simultaneamente, coexistiam a punição e a assistência, por um lado, e a educação e a rentabilidade económica, por outro, só poderia ter tido a sua origem em países permeados pela ética protestante (cf. Bronislaw Geremek, 1986) ${ }^{11}$.

A Inglaterra foi o país percursor deste movimento com a criação das primeiras instituições de enclausuramento no decorrer de meados do

\footnotetext{
${ }^{9} \mathrm{Na}$ análise que faz da Rasphuis de Amesterdão, Michel Foucault dá-nos uma ideia do modelo organizacional subjacente a esta instituição tendo em vista a reeducação, adestramento dos indivíduos - «um horário estrito, um sistema de proibições e de obrigações, uma vigilância contínua, exortações, leituras espirituais, todo um jogo de meios para "atrair para o bem" e "desviar do mal" enquadrava os detidos no dia-adia» (1975-a: 107-108).

${ }^{10}$ Apesar de ser discutível a sua eficácia económica (tanto nestas como em outras instituições de enclausuramento), esta era a crença dos fundadores deste modelo que, gradualmente, viriam subvalorizar a dimensão socioeducativa (móbil primo da sua instituição) face à dimensão económica, apostando, essencialmente, no fornecimento de mão-de-obra barata às manufaturas locais (Bronislaw Geremek, 1986).

${ }^{11}$ Este autor, não concordando totalmente com este ponto de vista, dado, em sua aceção, haver exemplos deste mesmo modelo em regiões de influência católica, opta por estabelecer uma conexão entre o mesmo e o grau de desenvolvimento económico de uma dada região. Isto é, a razão prima para o facto de o modelo ter sido implementado, primariamente e de um modo mais acentuado, nas cidades flamengas e alemãs, encontrava-se, essencialmente, no facto de as mesmas se enquadrarem em zonas economicamente desenvolvidas e, não tanto, por aí predominar a ética protestante.
} 
século XVI. Mas, seria somente a partir de finais deste século que, na sequência do aprofundar das críticas (tanto de natureza económica aumento significativo da taxa, como de ordem moral - emergência de uma cultura de dependência) à organização dos socorros assentes no outdoor relief ${ }^{2}$, esta nova orientação política face à pobreza viria a ganhar um novo impulso ${ }^{13}$. Deste modo, gradativamente, foi-se assistindo a uma inflexão no sentido de os socorros passarem a ser prestados institucionalmente (indoor relief). Seria neste contexto que o Poor Relief Act de 1722 viria a formalizar $^{14}$ a autorização de as paróquias (individualmente ou em conjunto) poderem construir casas onde os indigentes deveriam ser alojados, supervisionados e postos a trabalhar, i.e., as workhouses (William Quigley, 1996).

Com funções múltiplas de, «prisão»/abrigo para os vagabundos ${ }^{15}$, «[...] atelier de trabalho para os válidos, hospício para os velhos e incuráveis, asilo para as crianças e hospital para os doentes» (Louis Rivière, 1902: 54), estas instituições viriam a dispersar-se pelo território britânico de uma forma assaz rápida, estimando-se - para a primeira metade da centúria de setecentos - a existência de perto de 200 estabelecimentos deste tipo (Bronislaw Geremek, 1986).

Antes de avançarmos, convém fazer uma chamada de atenção. Apesar de poder ser enquadrado no movimento de enclausuramento em análise, o modelo britânico, comparativamente ao francês, apresenta, por um lado,

${ }^{12}$ Uma das críticas endereçada a este tipo de socorros interligou-se, mais uma vez, com a esfera do trabalho. Devido à inexistência de espaços suficientes, a assistência pelo trabalho era feita na habitação do próprio indivíduo, sendo-lhe fornecido o material necessário para as suas tarefas. Segundo os críticos, este sistema não permitia uma supervisão adequada do trabalho desenvolvido o que, em última análise, conduzia ao não alcance do objetivo de reeducação por via do trabalho (William Quigley, 1996).

${ }^{13}$ Um outro exemplo precoce deste movimento surge, igualmente, em Roma onde, na sequência de um afluxo muito grande peregrinos/mendigos, um édito de Gregório XIII (1572-1585) preconizou a instituição de um hospital-geral (1581) com as funções simultâneas de asilo e de atelier que viria a funcionar durante alguns anos como locus de encerramento (Bronislaw Geremek, 1986).

${ }^{14}$ Formalizar, na medida em que aos particulares já era permitido construir, havendo já alguns modelos deste tipo de casas, podendo-se referir como exemplo a existente em Bristol desde 1697.

${ }^{15}$ Por norma todas as workhouses possuíam um casual ward, i.e., um espaço celular destinado a receber, por um lado, os internos amotinados e, por outro, os pobres passantes por um período relativamente curto, normalmente uma noite. Inicialmente, os pobres poderiam socorrer-se destes abrigos sem terem de pagar nada em troca, mas, posteriormente, passou a ser aplicada uma taxa de permanência, só sendo permitido o abandono da instituição após a realização de uma qualquer tarefa previamente prescrita (Émile Chevallier, 1895; Louis Rivière, 1902). 
como teremos oportunidade de ver, similitudes no respeitante à proibição dos socorros domiciliários, mas, por outro, revela, também, diferenças significativas, porque, contrariamente ao ocorrido no Hospital Geral, nas workhouses os indivíduos não eram internados coercivamente, a recusa do internamento implicava «somente» a perca do direito à assistência. Por outras palavras, o internamento na workhouse, formalmente, consubstanciava-se como uma condição prévia, uma caução à prestação de socorros. A opção de entrar (ou não) cabia, em última instância, ao indivíduo, só se este desejasse ser socorridos é que ia para o estabelecimento. Mas, ao tomar em consideração a experiência concreta, facilmente se percebe que a situação de extrema miséria vivenciada pela maioria, acabava por transmutar a opção em obrigação e, por maiores que fossem os receios do internamento ${ }^{16}$, a necessidade de assegurar, minimamente, a sobrevivência não lhes deixava outra alternativa que não fosse a de socorrer-se da workhouse como último recurso, ou seja, a instituição acabava por se transformar na «pedra toque da miséria» (Léon Lallemand, 1910).

Regidas por uma disciplina rígida com o fito de diminuir a atração pelos socorros públicos (funcionava como um teste de desamparo) ${ }^{17}$, com o passar dos anos, dos dois grupos (válidos/inválidos) admitidos, o segundo tornou-se muito mais preponderante do que o primeiro. Os intuitos iniciais de corrigir pelo trabalho foram esmorecendo, ficando quase só com a função de assistência aos inválidos. De acordo com William Quigley (1996), a previsão inicial de redução dos custos com a substituição do outdoor pelo indor relief, dado se pensar que as instituições proviriam à sua própria manutenção por via dos produtos obtidos com o trabalho dos internos, acabaria por não se concretizar verificando-se, isso sim, um aumento dos custos afectos à assistência. Na segunda metade do século XVIII, a «workhouse não era mais uma

\footnotetext{
${ }^{16}$ Sobre este aspeto, cf. Émile Chevallier (1895).

${ }^{17}$ O objetivo último era o de que os trabalhadores pobres não fossem incentivados a desligar-se da esfera do trabalho, ou seja, encontramo-nos face ao princípio de «less eligibility» cujo pressuposto era o de que «os auxílios e atribuições de recursos devem ser sempre inferiores à mais baixa remuneração que um indivíduo poderia obter com uma atividade "normal". Assim, para entrar nesse sistema, é necessário estar reduzido à mais extrema necessidade ou ser obrigado por uma força externa ou pelo medo» (Robert Castel, 1995: 185). Segundo a aceção de Eric A. Posner «a workhouse fornecia alimentação, roupa e abrigo suficientes, mas restringia as relações familiares e sociais, o movimento, o consumo de álcool e tabaco, entre outros gastos. O propósito era o de transformar a ajuda recebida em algo de tal modo desgastante ao nível psicológico e estigmatizante moralmente, de modo que só os verdadeiramente necessitados o requisitassem, i.e., pretendia-se prevenir a fome e a falta de habitação sem criar um desincentivo ao trabalho» (apud William Quigley, 1996: 110).
} 
instituição de trabalho, [...] e não era mais utilizada como meio de aferir o pauperismo voluntário, não funcionava mais como o teste, servia, isso sim, de asilo para os velhos, os inválidos, as mães sobrecarregadas de filhos ilegítimos, as criancinhas ${ }^{18}$; ela acabou por perder o seu nome tornando-se uma poorhouse» (Émile Chevallier, 1895: 36; cf. Othenin d'Haussonville, 1895: 431; Léon Lallemand, 1910: 241). A partir da década de 80 deste século, os pobres válidos deixam de ser admitidos nestas instituições ${ }^{19}$, passando a defender-se, não mais 0 enclausuramento, mas, o fornecimento de trabalho.

\section{LE GRAND ENFERMEMENT: O MODELO FRANCÊS}

$$
\begin{aligned}
& \text { «Since you separated } \\
& \text { yourself from your } \\
& \text { group, we are going to } \\
& \text { separate you definitely } \\
& \text { or temporarily from } \\
& \text { society» } \\
& \text { (Michel Foucault, 1973). }
\end{aligned}
$$

Em França, um dos primeiros sinais da inflexão ocorrida na «política social» até aí desenvolvida surgiu, em 1544, com a criação do Grand Bureau des Pauvres por Francisco I (1515-1547). A menção ao mesmo justifica-se na medida em que a sua instituição pode ser considerada como uma das primeiras tentativas de reorganização/racionalização da assistência em solo francês. No fundo, pretendia-se fazer do Grand Bureau o órgão de cúpula da rede de organizações de caridade existentes. $\mathrm{Na}$ linha da política que vinha a ser seguida, este passou a deter sob a sua intendência a polícia dos mendigos. Logo, para além de instituição de caridade era, também, um «instrumento de polícia», i.e., simultaneamente, «local» de assistência e de internamento dos indivíduos acusados de delitos de mendicidade. Função que viria a desempenhar até às reformas ocorridas em $1612 \mathrm{e}$, mais especificamente, em 1656.

Um édito de 1612, da rainha regente Maria de Médicis, determina o estabelecimento de instituições em Paris, para o alívio dos verdadeiros pobres e a punição dos maus (G. de Chamborant, 1842).

\footnotetext{
${ }^{18}$ De acordo com Édouard Ducpetiaux (1843), em 1840, as workhouses «acolhiam» 64570 crianças com idade inferior a 16 anos.

${ }^{19}$ Em 1782, o Gilbert's Act determinou a proibição de admissão de todo e qualquer válido, passando a ser permitida somente a institucionalização de órfãos e/ou outros indigentes impotentes. Dever-se-á, igualmente, assinalar que, devido à elevada mortandade entre as crianças internadas, já desde 1767 tinha sido proibida a admissão de crianças com idade inferior a 6 anos (William Quigley, 1996).
} 
Sequencialmente, os vagabundos «estranhos» passaram a ficar sujeitos ao banimento (mulheres) ou às galeras (homens) ${ }^{20}$; quanto aos autóctones, para estes foi criado o Hôpital des Pauvres Enfermez, destinado ao internamento de três grupos de pobres: (i) os homens válidos, (ii) as mulheres e as crianças abaixo de oito anos e (iii) os inválidos, dos dois sexos, absolutamente incapazes de trabalhar. Para os primeiros deveriam ser destinados «trabalhos longos e duros e uma alimentação muito austera» e, para os restantes, ocupações de acordo com as suas capacidades. Neste caso, tal como em todo um conjunto de «fortalezas da ordem moral» paulatinamente edificadas um pouco por toda a Europa para o internamento dos «pecadores castigados por Deus», a «[...] exigência do trabalho está subordinada a um exercício de reforma e coação morais que proporciona, se não no sentido último, pelo menos a justificativa essencial do internamento» (Michel Foucault, 1972: 75). Com uma vigência exígua (o funcionamento do hospital não foi além dos 5 anos), mais um vez os intentos não foram alcançados, podendo assinalar-se como comprovativo da falácia deste projeto quanto ao fechamento dos indesejáveis, o elevado número de mendigos que grassavam em Paris alguns anos depois - «[...] a maldição da mendicidade continuava a angustiar a França. Em 1640, havia quase 40 mil mendigos no seio da capital; eles aumentavam todos os dias; eles provocavam todas as desordens, ameaçavam a tranquilidade pública» (Joseph-Marie de Gérando, 1839: 486; cf. Louis Rivière, 1902).

Alguns anos mais tarde, a situação viria, no entanto a modificar-se drasticamente. Podendo ser considerado como o símbolo da inflexão política ocorrida em França, o édito de 1656 promulgado por Luís XIV (1643-1715), é revelador das novas precauções tomadas pelo poder régio no sentido de minorar a problemática conexa com a mendicidade e a vagabundagem $\mathrm{e}$, por conseguinte, dos intuitos de instaurar $\mathrm{o}$ ordenamento e a disciplina no espaço público. Curiosa é, desde logo, uma das justificações apresentadas, no preâmbulo da lei, para a adoção desta política. De acordo com a mesma, as medidas a implementar, não obstante retrospetivamente evidenciarem uma clara preocupação com a segurança pública, não deveriam ser encaradas como uma medida de polícia, mas, antes, como uma política que tinha subjacente motivos

\footnotetext{
${ }^{20}$ Recorrentemente esta pena foi surgindo em diferentes decretos, estando por norma associada á reincidência. Quanto à aplicação concreta da mesma, Léon Lallemand (1910), apoiando-se em diferentes autores, é de opinião de que a mesma dificilmente foi aplicada em França pelo delito de vagabundagem/mendicidade de per si, ou seja, a opção pela aplicação da pena das galeras só ocorria quando esses se faziam acompanhar de outro tipo de delitos; quedando-se, por isso, a sua função, essencialmente, ao nível do medo inspirado nos indivíduos por uma possível condenação deste tipo.
} 
caridosos, no sentido em que o que era alvo de preocupação era a desmoralização dos costumes. Era aí que se encontrava a fonte de todos os problemas, ou seja, o fim último do enclausuramento dos «pobres mendigos» seria a correção da sua moral religiosa, dado a maioria deles «[...] de um e de outro sexo, habitarem em conjunto sem estarem casados, muitos dos seus filhos não serem batizados e eles viverem quase todos na ignorância da religião, no desprezo dos sacramentos e com um hábito continuado dos piores vícios» (Code de L'Hôpital-Général de Paris, 1786: 262) ${ }^{21}$.

Embora aceitando a presença desta preocupação, pensamos que mesma, quando comparada com a questão da segurança pública, vê diminuída a sua importância, não podendo, por isso, ser considerada como a pedra toque do desencadear da ação. Deste modo, não descurando às reticências levantadas pelos poderes eclesiásticos a algumas das reformas levadas cabo no âmbito da assistência, esta justificação deverá ser apreendida como um subterfúgio utilizado pelo poder régio para esconder as verdadeiras intenções e, desta forma, facilitar a concordância dos poderes religiosos face às reformas a implementar.

Visando, então, libertar a cidade de mendigos, o édito luisiano, para além de proibir a todo e qualquer indivíduo a prática da mendicidade ${ }^{22} \mathrm{e}$ a dádiva direta de esmolas ${ }^{23}$, determinou, igualmente, que «todos os pobres mendigos, válidos e inválidos, sem distinção de sexo ou de idade, deveriam ser encerrados num hospital, para serem, [por um lado,] de acordo com as suas capacidades, empregues nas obras, manufaturas e outros trabalhos» ${ }^{24}$ e, por outro, «instruídos e consolados

${ }^{21}$ Esta justificação, pode ser enquadrada no âmbito da asserção de Michel Foucault, segundo a qual o indivíduo enclausurado «[...] antes de ser objeto de conhecimento ou piedade, ele é tratado como sujeito moral» (1972: 62).

${ }^{22}$ Relativamente aos mendigos/vagabundos de fora de Paris encontrados a mendigar, com exceção dos padres (enviados para as respetivas dioceses) e aqueles provenientes de lugares onde houvesse instituições de enclausuramento ou que possuíssem meios para os sustentar (enviados para essas paróquias), seriam presos.

${ }^{23}$ A recorrência desta proibição, em distintos atos legislativos, e o gradual aumento das multas a aplicar, consubstancia-se, em nosso entender, como um indicador clarividente de que a dádiva de esmolas continuou a ser uma prática regular por parte das populações, ou seja, o «dever de consciência» sobrepunha-se aos atos legislativos. Igualmente importante, é o facto de esta interdição incluir uma exceção, i.e., encontrámos várias referências conducentes à conclusão de que a dádiva de esmolas, quando feita no domicílio do próprio, não era proibida no caso dos pobres envergonhados. A razão de ser para tal exceção encontrava justificação no estatuto especial detido por este grupo, estatuto esse, resultante do facto de os mesmos não serem responsabilizados pela situação em que se encontravam.

${ }^{24}$ Havia alguns casos específicos cuja «admissão» se encontrava interdita e/ou para os quais o hospital não se encontrava destinado, nomeadamente os: soldados 
espiritualmente» (Code de L'Hôpital-Général de Paris, 1786: 262, 266) num mesmo processo previa-se a exclusão espacial e a integração cultural (Paul Rabinow et all, 1982). No fundo visava-se, por via do enclausuramento, corrigir os indivíduos considerados inúteis, metamorfoseando-os em algo de útil/produtivo para a sociedade, «é a primeira vez [em França, MM] que se substituem as medidas de exclusão puramente negativas por uma medida de detenção; o desempregado não é mais escorraçado ou punido; toma-se conta dele, às custas da nação mas também da sua liberdade individual» (Michel Foucault, 1972: 65). A única esperança ao dispor dos indivíduos para escapar ao enclausuramento, era a de conseguirem uma ligação à esfera do trabalho, ligação essa, como sabemos, impossível de ser estabelecida pela maioria.

\subsection{Hospital Geral de Paris: Espaço Disciplinador e de Redenção Moral}

Para levar a cabo esta tarefa, procedeu-se a uma reorganização institucional reagrupando os pequenos estabelecimentos existentes, sob uma única administração, num de grande dimensão denominado HôpitalGénéral des Pauvres ou, como viria a ficar mais conhecido, Hospital Geral de Paris. Enquadrando distintos edifícios, do Hospital Geral faziam parte:

(i) Maison de la Pitié, para além de enquadrar a administração do hospital, funcionava igualmente como armazém. Era aqui que os futuros «hóspedes» eram recebidos de modo a ser feita a «triagem» que os distribuiria pelas restantes dependências; nesta instituição ficavam as crianças dos 4 aos 12 anos;

(ii) Bicêtre - pobres do sexo masculino: velhos, crianças, paralíticos, escrofulosos, loucos epiléticos, presos por ordem régia;

(iii) Salpêtrière - essencialmente mulheres: crianças, velhas, fracas, cegas, loucas, paralíticas, presas condenadas, prostitutas, grávidas;

(iv) Sainte-Pélagie - mulheres presas por deboche e raparigas arrependidas;

(v) Hôpital du Saint-Espirit - crianças dos dois sexos e órfãos;

(vi) Scipion - armazém de alimentos.

velhos/estropiados; leprosos, portadores de doenças contagiosas ou venéreas; pobres envergonhados e pobres mendigos casados. Quanto aos últimos, inicialmente, por questões logísticas, a estes eram fornecidos socorros domiciliários, mas, devido aos elevados gastos implicados por este tipo de alívio (cerca de 3000 indivíduos eram socorridos desta forma), os mesmos passaram a ser admitidos a partir de 1661, sendo instalados em Salpêtrière. Quanto aos doentes em geral, não estava prevista a sua admissão, caso adoecessem após o internamento deveriam ser enviados para o HôtelDieu. 


\section{Figura 2}

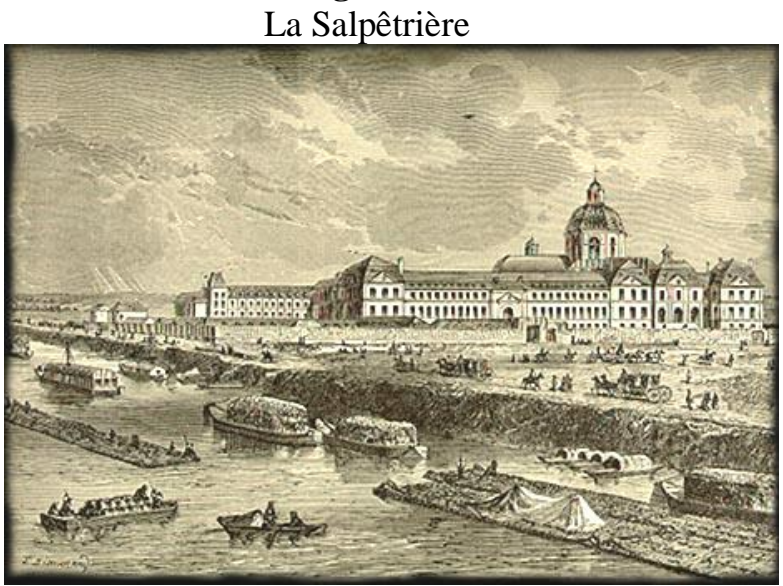

Fonte: Gourdon de Genouillac (1882)

Os diretores do estabelecimento ${ }^{25}$, dotados de poderes judiciais, passaram a deter amplos poderes discricionários para fazer aplicar interna e externamente - as medidas de polícia destinadas aos pobres na cidade e arredores de Paris ${ }^{26}$. Em 1657, a instituição abriria as suas portas e, daqui em diante, o preço a pagar para ter «direito» a ser socorrido passou a ser o da perca da liberdade total. Devendo-se, igualmente, acrescentar que, mesmo o pressuposto direito de sustentação dos inválidos, em muitas ocasiões, não viria a passar de uma mera intenção devido não só, mas também à escassez de recursos, por um lado, e à manifesta intenção de transformar o internamento em algo muito duro, quase impossível de suportar de modo a não ser desejado pelos considerados falsos pobres.

\footnotetext{
${ }^{25}$ Léon Lallemand (1910), dá-nos conta do convite feito a São Vicente de Paula para dirigir os destinos da instituição, no entanto, o mesmo viria a ser recusado com o fundamento da dúvida de se os objetivos preconizados para o Hospital estariam em conformidade com os dogmas da igreja.

${ }^{26}$ Convém assinalar, mais uma vez, que a caça aos mendigos/vagabundos não era uma prática bem aceite pelos estratos mais baixos da população. Estes, considerando-a como uma ofensa a Deus, para além de não seguirem a determinação do édito (reter os vagabundos que fossem pedir esmola a suas casas, entregando-os de seguida ao hospital), revoltavam-se, existindo vários testemunhos do levantamento de insurreições populares contra os arqueiros do hospital e os beleguins (corpo especial de polícia da instituição) aquando do desempenho das suas tarefas. Para vários exemplos, cf. Code de L'Hôpital-Général de Paris (1786: 23-26; 417-419; 465-466); Alexandre Monnier (1856: 350); Louis Rivière (1902: 12).
} 
Apesar de se poder conjeturar que Paris foi, momentaneamente, libertada ou, mais adequadamente, aliviada dos «seus» mendigos em consonância com a construção de «enclaves de miséria» para onde foram relegados os indesejáveis (Bronislaw Geremek, 1986), esta situação não perdurou por muito tempo. Mais uma vez, tal como na sequência de políticas precedentes, foi-se assistindo, periodicamente, a um movimento de ioió, deslocando-se o problema da cidade para o campo (subsequentemente à implementação de um acto legislativo) e deste novamente para a cidade após o esmorecimento da lei e/ou na sequência da agudização das condições de experiência ${ }^{27}$. Um comprovativo do referido é-nos fornecido, em 1661, por um novo édito real que, reafirmando as determinações anteriores, mandava prender todos os mendigos válidos e os que fossem de novo apanhados a mendigar, após terceira reincidência, deveriam ser chicoteados em público e seguidamente condenados: as raparigas e as mulheres ao chicote, rapadas $^{28}$ e banidas de Paris por 10 anos; os homens a 5 anos de serviço nas galeras (Code de L'Hôpital-Général de Paris, 1786: 419) ${ }^{29}$. Em 1662 apesar do hospital albergar mais de 6000 pobres, o seu objetivo primário de eliminação da mendicidade das ruas acabou por não ser totalmente bem sucedido, visto os socorros fornecidos terem atraído mais pobres à cidade na esperança de serem assistidos. Assim, nesse ano determinou-se a criação de instituições similares por todo o reino - uma obra de execução difícil e morosa ${ }^{30}$.

A transformação da instituição num incomensurável depósito de pobres, e a contínua afluência de novos pobres a Paris, obrigou a que o enclausuramento indiscriminado viesse, gradualmente, a ser substituído por uma seleção criteriosa das admissões. Para além de se tomar em consideração o domicílio dos socorros, a partir de 1680 passou a definirse claramente os tipos de pobres que podiam ser admitidos:

\footnotetext{
${ }^{27}$ Para uma descrição da miséria profunda que grassava na França deste período a par com as sumptuosidades de Versalhes, vidé Jules Siegfried (1877).

${ }^{28} \mathrm{O}$ corte de cabelo, era um outro meio recorrentemente utilizado pelas autoridades para a identificação dos pobres delituosos.

29 Podendo querer indiciar uma nova estratégia na sequência de possíveis condicionalismos de lotação, em 1685 a condenação às galeras passa a ser aplicada logo aquando da primeira detenção dos mendigos válidos.

${ }^{30}$ Para uma análise do envolvimento e apoio dos poderes eclesiásticos à prossecução dessa tarefa, em especial de alguns elementos jesuítas, cf. Léon Lallemand (1910). Segundo a ótica de Michel Foucault (1972), a prescrição de alastramento dos hospitais a todo o reino só viria a surgir em 1676, no entanto, com base em fontes por nós consultadas, pensamos poder asseverar ser 1662 a data correta dessa mesma prescrição.
} 
inválidos: crianças com idades inferiores a 13 anos (raparigas) e 15 anos (rapazes); velhos, dos dois sexos, com idade igual ou superior a 60 anos; os epiléticos; provisoriamente, os cegos e os incuráveis; os doentes venéreos; os alienados;

os mendigos válidos, com idade superior a 16 anos, seriam presos e adstritos aos trabalhos mais duros que as suas forças permitissem (Code de L'Hôpital-Général de Paris, 1786: 494$496)^{31}$.

Apesar dos esforços levados a cabo para libertar o espaço público dos seres indesejados, em inícios do século XVIII o poder régio continuava a não estar satisfeito com os resultados alcançados. Demonstrativo deste ponto de vista é uma declaração real de 1724, onde são aventadas, por um lado, algumas das razões para o não alcance pleno dos objetivos estabelecidos em 1656 - quiçá uma confissão literal do seu fracasso, e, por outro, apresentadas novas medidas visando a solução da problemática.

De acordo com o preâmbulo, as causas para os insucessos eram de vária ordem: «a execução [dos distintos decretos] não foi levada a cabo de modo igual em todo o reino, os mendigos perseguidos nas principais cidades tiveram a facilidade de se afastar para outros lugares, continuando na mesma libertinagem dado lhes ser permitido regressar posteriormente aos locais onde antes tinham sido perseguidos; não fornecemos os meios

${ }^{31}$ No concernente à importância assumida pela esfera do trabalho, segundo a aceção de Bronislaw Geremek, no Hospital Geral, contrariamente ao praticado pelo modelo flamengo/alemão, não existia a preocupação prima de extrair lucro a partir do mesmo: o trabalho forçado, para além de não ser rentável, acarretava custos, mas isto «[...] não parecia incomodar as autoridades, uma vez que o que se pretendia com este método não era extrair proveitos económicos da mão-de-obra disponível mas realizar um programa de educação social e religiosa ensinando os pobres a prezar o trabalho e a vida laboriosa» (1986: 261). Encontramo-nos perante o que Robert Castel denomina, num outro contexto, de «valor redentor máximo do trabalho para um benefício económico nulo» (1995: 228). Para outros exemplos da ineficácia produtiva do trabalho, no modelo francês, cf. Robert Castel (1995: 182-183). Se esta ineficácia pode encontrar justificação no facto de a dimensão produtiva não ter sido ereta como objetivo primo do enclausuramento no modelo francês, o mesmo já não ocorre quando tomamos em consideração alcance do objetivo de realização de um «programa de educação social e religiosa». Mas também nesta dimensão os sucessos alcançados não parecem ter sido muito significativos; na análise que faz das instituições totalitárias, Robert Castel levanta sérias dúvidas quanto à sua eficácia, dúvidas essas, justificadas com base nos contrastes existentes entre «[...] os regulamentos dessas instituições que falam de trabalho, de obediência aos preceitos morais e religiosos e os testemunhos e as queixas sobre o seu funcionamento real que denunciam unanimemente o reinado da fraude e do vício. À venalidade e ao sadismo dos guardas corresponde a ociosidade, a devassidão, as rixas e o espírito de revolta dos reclusos» (1978: 92; cf. 119). 
necessários à manutenção dos hospitais, o que obrigou a que, em distintos locais, os directores dos hospitais fossem obrigados a abrir as portas àqueles que aí se encontravam fechados; não fornecemos trabalho e asilo aos mendigos válidos que o não podiam encontrar, o que lhes forneceu um pretexto para transgredir a lei; [...] e, por fim, as penas pronunciadas não foram muito severas e não havia nenhum meio de reconhecer aqueles que eram presos várias vezes de forma a puni-los mais severamente pela reincidência» (Code de L'Hôpital-Général de Paris, 1786: 459) ${ }^{32}$.

Quanto às medidas com o intuito de solucionar o problema, será ao nível destas que a declaração ganha especial interesse, dado pensarmos poder ser este considerado um dos primeiros documentos onde, explicitamente, se adota uma nova classificação dos pobres. Reconhecendo de modo formal que a inatividade podia dever-se a causas alheias à vontade do próprio indivíduo ${ }^{33}$, advogava-se ser necessário fornecer trabalho a todo o mendigo válido que o não encontrasse pelos seus próprios meios, pois, só dessa forma seria possível «[...] distinguir o verdadeiro pobre que merece todos os socorros e compaixão, daquele que se encobre falsamente com o seu nome para lhe roubar a sua subsistência», eliminando, assim, os argumentos do último quanto à necessidade de pedir esmolas (Code de L'Hôpital-Général de Paris, 1786: 460). A dicotomia inválidos/válidos continuava presente, no entanto, para os últimos passou a ser estabelecida uma nova subdivisão, i.e., entre os que queriam trabalhar e, por isso, deviam ser ajudados, e os ociosos por vontade própria, devendo para estes, para além do encerramento, ser reservadas penas mais severas. Logo, visando o estabelecimento da distinção, determinou-se que os mendigos válidos e capazes de ganhar o seu sustento deveriam arranjar um emprego e se, no prazo de quinze dias, não o obtivessem, deveriam dirigir-se ao hospital para serem inseridos em trabalhos públicos ${ }^{34}$ e sustentados;

\footnotetext{
${ }^{32}$ Um outro exemplo, mais remoto, da incapacidade institucional para fornecer trabalho aos detidos, é-nos fornecido por Bronislow Geremek. Este autor ao se referir à Bridewell londrina, afirma que nos inícios do século XVII passaram por esta instituição «[...] cerca de 1000 vagabundos, a maior parte dos quais, não tendo aí emprego, são julgados, punidos e devolvidos à procedência» (1986: 252).

${ }^{33}$ Dever-se-á assinalar a presença desta ideia (ainda que, não de forma tão explicita por forma a propugnar a adoção de medidas adequadas à mesma), numa ordenança real de 1662. Na mesma, apontavam-se a ociosidade, a falta de trabalho e, ainda, a situação de grande necessidade existente na província, como sendo as principais razões do aumento da afluência de mendigos a Paris, (Code de L'Hôpital-Général de Paris, 1786: 423).

${ }^{34}$ De acordo com Louis Rivière (1902), para a prossecução dos mesmos, previu-se a implementação de ateliers, no entanto, estes, mais uma vez, acabariam por ter uma duração exígua e poucos efeitos práticos.
} 
posteriormente, se encontrassem um trabalho por via do qual pudessem subsistir ser-lhes-ia dada autorização para sair da instituição. Quanto aos inválidos (crianças, velhos, mulheres grávidas), deveriam apresentar-se voluntariamente nos hospitais para serem sustentados «gratuitamente», sendo empregues, de acordo com as suas forças, em tarefas determinadas pela instituição e em benefício desta, caso não o fizessem seriam, igualmente, coagidos ao encerramento.

Independentemente das inovações introduzidas por este acto legislativo e de outros que lhe sucederam, a problemática continuou sem solução visível ${ }^{35}$. Pouco a pouco, os «hospitais gerais foram-se transformando em simples asilos de abrigo para velhos, mulheres e órfãos, recusando-se a admitir vagabundos, mendigos incorrigíveis, pois ninguém estava preparado para receber esses hóspedes perigosos. Tal como no passado, a praga dos falsos pobres alastrou-se e a realeza viu-se obrigada a recorrer aos Depósitos de Mendicidade» (Léon Lallemand, 1910: 272). Portanto, dada a incapacidade logística para encerrar mais indivíduos, a partir de 1764, somente os inválidos continuaram a ser enclausurados nos hospitais, determinando-se claramente os indivíduos que se enquadravam dentro desta categoria, designadamente os velhos com idade igual ou superior a 70 anos, os inválidos, as crianças e jovens até aos 15 anos, as mulheres e as raparigas ${ }^{36}$.

${ }^{35}$ De entre as razões subjacentes à insolubilidade da questão, dever-se-á pontuar as mutações que, de acordo com Robert Castel (1995), ocorreram no seio da problemática da pobreza a partir deste período. Destarte, segundo a aceção deste autor, a partir de finais da centúria de seiscentos, o fenómeno começa a adquirir características de massa. A morte que, até aqui, tinha funcionado como elemento regulador do equilíbrio económico e social, ao minorar essa função acaba por propugnar um aumento da pressão demográfica que, aliada a outros fatores económicos, acaba por produzir a transmutação de uma «pobreza de massa secular» em «vulnerabilidade de massa» que acarreta consigo novos problemas e novas preocupações, dado o estreitamento significativo ocorrido entre o hiato (já de si fluido) anteriormente existente entre os mendigos/vagabundos indigentes e os estratos mais baixos da população pobre. Consequentemente, «o carácter inaceitável da miséria e os riscos de dissociação nela contidos [indigência] deixam então de atingir essencialmente esses elementos, em resumo marginais, que são os assistidos e os desfiliados. Tornam-se um risco que afeta a condição laboriosa enquanto tal, isto é, a maioria do povo da cidade e do campo. A questão social vai tornar-se a questão criada pela situação de uma parte do povo enquanto tal e não apenas por suas franjas mais estigmatizadas» (1995: 220).

${ }^{36}$ Poucos anos antes de a Revolução estalar, só em Paris, havia cerca de 20000 hospitalizados, dos quais 12000 se encontravam internados no Hospital Geral, 3000 nos Inválidos, 2500 no Hotel-Dieu e os restantes em outras fundações existentes na cidade (Robert Castel, 1978: 65). 
Quanto aos válidos, a pena do banimento deu lugar ao serviço nas galeras e, para solucionar a questão logística, a partir de 1768, iniciou-se de modo acelerado o enclausuramento dos mesmos nos depósitos de mendicidade existentes. Nesse mesmo ano havia cerca de 80 estabelecimentos de carácter penitenciário desse tipo, no entanto, gradualmente, o seu número foi sendo reduzido, não ultrapassando os 34 em $1793^{37}$. Isto não significa que os mesmos não tivessem desempenhado a sua função, nem que seja enquanto locus de morte, pois, «entre 1768 e $1772,111.836$ pessoas "entraram nos depósitos, contra 1.132 condenações às galeras. São colocados em prédios insalubres, sem higiene nem cuidados médicos. A mortalidade nesses locais é espantosa: 21.339 mortes durante os mesmos quatro anos» (Robert Castel, 1995: 127; cf. Jules Siegfried, 1877) ${ }^{38}$.

\section{NOTA CONCLUSIVA}

Buscando uma síntese do campeamento encetado, poder-se-á referir que a dupla vertente subjacente ao movimento do enclausuramento, i.e., «precaução social» e «medida económica» (Michel Foucault, 1972), se traduziu praticamente em algo de complexo. Quanto à importância das mesmas para o despoletar do processo, embora cientes da existência de uma interligação estrita entre as duas, pessoalmente, advogamos ter sido a vertente da «precaução social» a razão prima para o iniciar desse mesmo movimento.

No tocante a esta vertente, como vimos, apesar de se poder considerar que, com o mesmo, se foi controlando/minorando por curtos períodos as desordens públicas, ciclicamente a problemática ressurgia ainda com mais força. Ainda dentro desta leitura, mas, evidenciando já uma maior

${ }^{37}$ Legislação napoleónica de 1808 vir-lhe-ia a dar um novo impulso ao determinar que cada departamento deveria possuir um estabelecimento deste tipo; consequentemente, «entre 1809 e 1814 foram criados 77 depósitos de mendicidade», mas, após este período, o seu número começou a decrescer novamente, cifrando-se o número dos mesmos, em finais dos anos setenta, em 42 (Jules Siegrief, 1877: 33; 98; cf. Émile Levasseur, 1892: 126-127). De acordo com Émile Chevallier (1889), em finais dos anos 80 não havia, nos 51 departamentos franceses, mais do que 28 depósitos e os propósitos iniciais com que os mesmos tinham sido criados encontravam-se significativamente diluídos, dado a população interna ser constituída, essencialmente, por velhos e incuráveis: em 1886, os 5389 internos subdividiam-se em 1237 reclusos e 4152 hospitalizados. Consequentemente, segundo o autor, «os depósitos quase deixaram de ser lugares de repressão, onde o trabalho era obrigatório, para se transformarem em refúgios, asilos, estabelecimentos hospitalares» (1889: 138).

${ }^{38}$ Para dados, igualmente alarmante, relativos ao ano de 1824, cf. Bigot de Morogues (1834: 197). 
proximidade à dimensão económica, não descurando a categorização associada aos indivíduos, com o enclausuramento dos mendigos válidos, explicitamente, visava-se retirar do espaço público os indivíduos que, segundo a ótica dos intervenientes, se furtavam ao trabalho, ou seja, partindo-se do pressuposto de que o não-trabalho era uma opção pessoal, defendia-se o internamento como a via mais adequada para reeducar os indivíduos para a o ethos do trabalho, ou seja, «pôr os mendigos a trabalhar tinha, pois, em primeiro lugar, um objetivo disciplinar» (Pierre Rosanvallon, 1995: 133).

A partir do momento em que o encaramos como «medida económica», constatamos que o enclausuramento serviu, por um lado, em períodos de crise, como um meio de reabsorção dos desempregados e, por consequência, de ocultação dos efeitos sociais associados ao nãotrabalho. Por outro, em períodos de expansão, consubstanciou-se como uma estratégia de controlo dos preços no mercado, porquanto os internos ao serem apreendidos como mão-de-obra barata acabavam por se transformar num elemento de concorrência com o qual se pretendia baixar os salários praticados na esfera do trabalho ${ }^{39}$. No entanto, segundo a aceção de Michel Foucault (1972), os intentos de manipulação do «mercado da mão-de-obra» e dos «preços de produção» por intermédio do enclausuramento não viriam a alcançar os objetivos desejados, pois, de modo equívoco, as instituições de internamento, apesar de absorverem «[...] os desempregados, faziam-no sobretudo para ocultar a miséria e evitar os inconvenientes políticos ou sociais de sua agitação. Mas, no exato momento em que se colocavam essas pessoas nos ateliers obrigatórios, aumentava-se o desemprego nas regiões vizinhas ou em sectores similares. Quanto à ação sobre os preços, ela só podia ser artificial, com o preço de mercado de produtos assim fabricados não tendo uma proporção com o custo real, se calculando de acordo com as despesas provocadas pelo próprio internamento» (1972: 70).

Deste modo, a ineficácia resultante dos objetivos associados ao internamento, acabaria por conduzir ao questionamento e, posterior, ocaso gradual do Grande Enclausuramento ${ }^{40}$. Assim sendo, a passagem

\footnotetext{
${ }^{39}$ Por um lado, o internamento funcionava como elemento condicionador dos salários, visto os rendimentos dos internos serem inferiores aos praticados no mercado. Por outro, a própria ameaça de internamento consubstanciava-se, igualmente, como um instrumento regulador, na medida em que o indivíduo, para não ver concretizado o espectro do enclausuramento, acabava por se sujeitar aos salários praticados, por mais baixos que os mesmos fossem.

${ }^{40}$ De acordo com a opinião de Michel Foucault, «consumido por ter servido de mais, ele bruscamente descobre os seus limites. Sabe-se agora que ele não pode resolver uma crise de desemprego, que não é suscetível de agir sobre os preços. Se tem ainda
} 
do século XVIII para o século XIX evidencia uma nova inflexão nas políticas adotadas face à problemática da pobreza. Inflexão essa onde, a par das críticas direcionadas às políticas repressivas até aí adotadas, bem como aos custos financeiros subjacentes às mesmas, mais uma vez, são possíveis de ser vislumbradas novas intenções económicas.

\section{REFERÊNCIAS BIBLIOGRÁFICAS}

Castel, Robert (1978). A Ordem Psiquiátrica: A Idade de Ouro do Alienismo (or. L'ordre Phychiatrique: L'âge d'or d'alienisme). Rio de Janeiro, Edições Graal (1991), 329 pp.

Castel, Robert (1995). As Metamorfoses da Questão Social: uma Crónica do Salário (or. Les Métamorphoses de la Question Sóciale). Petrópolis, Editora Vozes (1998), 611pp.

Castel, Robert (2000). The Roads to Disaffiliation: Insecure Work and Vulnerable Relationships. In International Journal of Urban and Regional Research. Vol. 24, n. ${ }^{\circ}$ 3. Oxford, Blackwell Publishing, pág. 519-535.

Chamborant, C. G. de (1842). Du Paupérisme. Ce qu'il Était dans l'Antiquité, ce qu'il Est de Nos Jours. Paris, Guillaumin, 496 pp.

Chevallier, Émile (1889). De L'assistance dans les Campagnes: Indigence, Prévoyance, Assistance. Paris, Arthur Rousseau, 436 pp.

Chevallier, Émile (1895). La Loi des Pauvres et la Société Anglaise: Organisation de L'assistance Publique en Angleterre. Paris, Arthur Rousseau, $412 \mathrm{pp}$.

Code de L'Hôpital-Général de Paris (1786). Recueil des Principaux Édits, Arrêts, Déclarations \& Règlements qui le Concernent. Paris, Imprimerie de la Veuve Thiboust, $642 \mathrm{pp}$.

Deleuze, Gilles (1998). Foucault. Lisboa, Edições Vega, 179 pp.

Ducpetiaux, Édouard (1843). De la Condition Physique et Morale des Jeunes Ouvriers et des Moyens de L'améliorer, Vol. I. Bruxelles, Méline et Cans, 444 pp.

Fokkens, Melchior (1662). Der Wijdt-vermaarde Koop-stadt Amstelredam. Amsterdam, Abraham, Jan de Wees.

Foucault, Michel (1972). História da Loucura (or. Histoire de la Folie à L’Âge Classique). São Paulo, Editora Perspectiva (2002), 551 pp.

um sentido, é na medida em que diz respeito a uma população indigente, incapaz de prover a suas necessidades. Mas não pode mais figurar, de modo eficaz, nas estruturas económicas» (1972: 404). 
Foucault, Michel (1973). Truth and Juridical Forms. In RABINOW, Paul

(Ed.) (2000). Power. Essential Works of Foucault 1954-1984. Vol.

III. New York, New Press, pág. 1-89.

Foucault, Michel (1975-a). Vigiar e Punir. Nascimento da Prisão, (or.

Surveiller et Punir, Naissance de la Prison), Rio de Janeiro, Editora Vozes (1993), 277 pp.

Foucault, Michel (1975-b). Os Anormais. Curso no Collège de France (1974-1975), (or. Les Anormaux), São Paulo, Martins Fontes (2001), $479 \mathrm{pp}$.

Genouillac, H. Gourdon de (1882). Paris à Travers les Siècles. Histoire

Nationale de Paris et des Parisiens Depuis la Fondation de Lutèce Jusqu'à nos Jours. Paris, F.Roy.

Gérando, Joseph-Marie de (1839). De la Bienfaisance Publique. Vol. IV. Paris, Jules Renouard, 620 pp.

Geremek, Bronislaw (1986). A Piedade e a Forca. História da Miséria e da Caridade na Europa. Lisboa, Terramar (1995), 303 pp.

Haussonville, Gabriel-Paul-Othenin d' (1895). Études Sociales: Socialisme et Charité. Paris, Calmann Levy, $500 \mathrm{pp}$.

Lallemand, Léon (1910). Histoire de la Charité. Les Temps Modernes: du $X V I^{e}$ Siècle au XIX $X^{e}$ Siècle. Vol. IV-1. Paris, Alphonse Picard et fils, $624 \mathrm{pp}$.

Levasseur, Émile (1892). La Population Française. Histoire de la Population Avant 1789 et Démographie de la France Comparée à Celle des Autres Nations au XIX Siècle. Vol. III. Paris, Arthur Rousseau, $569 \mathrm{pp}$.

Menezes, Manuel (2009). Riscos e Protecção Social nos Alvores da Europa Moderna. Vila Nova de Gaia, Corpos Editora, 253 pp.

Monnier, Alexandre (1856). Histoire de L'assistance dans les Temps Anciens et Modernes. Paris, Guillaumin, 568 pp.

Morogues, Pierre Marie Sébastien Bigot de (1834). Du Paupérisme, de la Mendicité et des Moyens d'en Prévenir les Funestes Effets. Paris, Prosper Dondey-Dupré, 675 pp.

Negri, Antonio; Hardt, Michael (2000). Império (or. Empire). Lisboa, Editora Livros do Brasil (2004), 510 pp.

Quigley, William P. (1996). Five Hundred Years of English Poor Laws, 1349-1834: Regulating the Working and Nonworking Poor. In Akron Law Review, Vol. 30, n. $^{\circ}$ 1, pág. 73-128. In URL: http://www.uakron.edu/law/lawreview/f96v30n1.php

Rabinow, Paul; Dreyfus, Hubert L. (1982). Michel Foucault. Uma Trajectória Filosófica, Para Além do Estruturalismo e da Hermenêutica (or. Michel Foucault, Beyond Structuralism and Hermeneutics). São Paulo, Forense Universitária (1995), 299 pp. 
Rivière, Louis (1902). Mendiants et Vagabonds. Paris, Victor Lecoffre, $239 \mathrm{pp}$.

Rosanvallon, Pierre (1995). La Nueva Cuestión Social. Repensar el Estado Providencia (or. La Nouvelle Question Sociale. Repenser L'État-providence). Buenos Aires, Ediciones Manantial (1995), 215 $\mathrm{pp}$.

Siegried, Jules (1877). La Misère: Son Histoire Ses Causes Ses Remèdes. Paris, Germer Baillière, 265 pp. 